\title{
O uso de registros paroquiais como possibilidade de combinação de estudos quantitativos com estudos de trajetórias individuais: um exercício aplicado às práticas de nominação ${ }^{1}$
}

Nathan Camilo $^{2}$

Resumo: Em consonância com o recente debate a respeito do uso de abordagens quantitativas em combinação com o estudo de trajetórias individuais, este artigo visa a refletir a respeito do uso de registros paroquiais como fonte para investigações que utilizem tal combinação de abordagens. A reflexão é aplicada às práticas de nominação adotadas pela população da freguesia Nossa Senhora Madre de Deus de Porto Alegre entre os anos de 1772 e 1835. A partir da análise quantitativa dos assentos paroquiais e da reconstituição de uma trajetória, é possível compreender de forma mais clara como o nome era utilizado pela sociedade da época. A forma como se davam os processos de atribuição, incorporação, variação e transmissão de prenomes, segundos nomes e sobrenomes indiciam um panorama onde o nome era considerado um patrimônio imaterial a ser administrado conforme as estratégias possíveis em uma sociedade estratificada.

Palavras-chave: Registros paroquiais. Práticas de nominação. Trajetórias. Patrimônio imaterial.

Resumen: En consonancia con el reciente debate a respecto del uso de abordajes cuantitativos en combinación con el estudio de trayectorias individuales, este artículo visa a reflectar a respecto del uso de registros

\footnotetext{
${ }^{1}$ Parte integrante do projeto de mestrado em andamento denominado: “É preferível bom nome a muitas riquezas": dinâmica das práticas de nominação no extremo sul do Brasil entre o final do século XVIII e o início do século XIX. Este trabalho está sendo realizado com apoio do CNPq, Conselho Nacional de Desenvolvimento Científico e Tecnológico - Brasil.

${ }^{2}$ Mestrando em História (UNISINOS-RS). Contato: natacam2@ gmail.com.
} 
parroquiales como fuente para investigaciones que utilicen tal combinación de abordajes. La reflexión es aplicada a las prácticas de nombramiento adoptadas por la población de la feligresía Nossa Senhora Madre de Deus de Porto Alegre entre los años de 1772 y 1835 . A partir del análisis cuantitativo de los asientos parroquiales y de la reconstitución de una trayectoria, es posible comprender de forma más clara como el nombre era utilizado por la sociedad de la época. La forma como se daban los procesos de atribución, incorporación, variación y transmisión de prenombres, segundos nombres y apellidos indician un panorama donde el nombre era considerado un patrimonio inmaterial a ser administrado conforme las estrategias posibles en una sociedad estratificada.

Palabras-clave: Registros parroquiales. Prácticas de nombramiento. Trayectorias. Patrimonio inmaterial.

\section{Apresentação}

O presente artigo tem por objetivo apontar possibilidades de investigação a partir do uso das fontes paroquiais e de suas potencialidades para estudos que façam uso combinado de análises de natureza quantitativa com estudos de trajetórias de caráter qualitativo.

$\mathrm{Na}$ pesquisa em questão, a combinação entre métodos quantitativos e qualitativos será aplicada às práticas de nominação adotadas pela população livre e forra da freguesia Nossa Senhora Madre de Deus de Porto Alegre no período compreendido entre os anos de 1772 e 1835. O objetivo é compreender os processos de atribuição, incorporação, variação e transmissão de prenomes, segundos nomes e sobrenomes. Também se busca entender a dinâmica dos nomes - a 
constituição de um nome ao longo de uma existência - e as motivações e implicações envolvidas nesses atos.

Este artigo será dividido em três partes. Inicialmente, serão apresentados os registros paroquiais como fonte de pesquisa para o tema proposto, com suas limitações e possibilidades. A seguir, o nome e as práticas de nominação serão analisados. Inicialmente, de forma quantitativa, com o estudo do estoque disponível e da transmissão dos nomes pela população. Num segundo momento, mediante a reconstituição de trajetórias individuais, tais assuntos serão abordados de forma a se entender como as práticas nominativas eram aplicadas ao longo de uma existência.

\section{Registros paroquiais e práticas nominativas}

Os registros paroquiais, conforme Maria Luiza Marcílio (2004), são fontes seriais de grande importância para estudos demográficos referentes à população católica ocidental. Isso porque estes, em tese, deveriam cobrir a integralidade de tal população, englobando pessoas das diversas condições social, jurídica e de legitimidade, cores e sexos, com uma grande riqueza de informações "para a reconstituição da história social e cultural das populações católicas e a potencialidade de explorações que permitem, para desvendar o passado em várias direções” (MARCílIO, 2004, p. 15). 
Contudo, Maria Silvia Bassanezi (2013, p. 147) afirma que o grau de abrangência dos dados encontrados nos registros paroquiais era variável. Os assentos alusivos a indivíduos de estratos sociais mais elevados possuíam dados mais completos e precisos do que os registros de escravos, forros ou livres dos segmentos sociais menos privilegiados, evidenciando os "preconceitos e valores de uma sociedade que hierarquizava as pessoas de acordo com sua condição social".

Para cada tipo de evento deveria haver um livro especial e exclusivo. Os estudos referentes às práticas de nominação costumam se valer primordialmente das informações contidas nos registros de batismo. Estes seguramente eram os mais próximos de cobrirem a universalidade da população, visto que nem todos se casavam perante a Igreja e era maior a chance de deixar de comunicar um óbito às autoridades. Ao mesmo tempo, de acordo com as Constituições Primeiras do Arcebispado da Bahia, elaboradas por Sebastião Monteiro da Vide (2007, original de 1707), era considerado "muito perigoso dilatar o Batismo das crianças, [...] [pois] morrendo sem ele, perdem a salvação" (VIDE, 2007, Livro 1, Título XI, p. 14).

Os assentos de batismo, contudo, se tomados isoladamente, só permitem a análise dos prenomes. Nas populações luso-brasileiras da época, segundos nomes e sobrenomes, quando era o caso, só eram incorporados em momentos posteriores da vida. Não há como se dizer com certeza a partir de que ponto esse ato ocorria. De qualquer forma, eram registrados nos atos de casamento e/ou falecimento do sujeito, o 
que implica na inclusão dos registros de casamento e de óbito à investigação.

Como fonte de natureza nominativa, os registros paroquiais permitem o cruzamento entre si e com outras fontes (BASSANEZI, 2013), tendo como fio condutor para identificação dos indivíduos o nome, o que Carlo Ginzburg (1989a) chama de método onomástico. Cruzando os dados dos assentos de batismo, casamento e óbito, se permitem análises de caráter tanto quantitativo quanto qualitativo, tanto em perspectiva demográfica quanto sociocultural, possibilitadas pelas informações dos registros paroquiais (BASSANEZI, 2013).

Além de genealogistas e biógrafos, os primeiros a explorarem as potencialidades dos registros paroquiais no Brasil foram os historiadores-demógrafos, a exemplo do que já ocorria na Europa desde os anos 60. Inicialmente, os estudos tinham caráter estritamente demográfico. Com o tempo e a influência da História Social e Cultural, os temas se multiplicaram (BASSANEZI, 2013). Um dos muitos temas foi:

A ocorrência de padrões de nominação ou nomeação dos indivíduos - através dos quais se observam: origens remotas das famílias; alianças com outros grupos sociais, étnicos e familiares; o ingresso de imigrantes nas sociedades $\mathrm{e}$ as decorrentes modificações ou transformações importantes nos usos, costumes, na organização social, política ou religiosa da comunidade. (BASSANEZI, 2013, p. 145). 
Com os estudos em Demografia Histórica, emergiu uma importante questão metodológica que envolve os nomes. De acordo com Norberta Amorim (1983, p. 213):

Por exigências de um estudo demográfico, quando nos debruçamos sobre os livros de registos de baptizados, casamentos e óbitos, [...] embora perseguindo os números, trabalhamos obrigatoriamente sobre nomes. Nenhum estudo de comportamentos demográficos terá validade, se não conseguirmos identificar de forma correcta cada indivíduo nos vários actos registados de sua vida [...]. Tal identificação parte basicamente do nome.

Entretanto, no devir da produção de trabalhos demográficos referentes a populações luso-brasileiras anteriores ao século $\mathrm{XX}$, foram encontradas certas particularidades referentes às práticas nominativas vigentes à época que dificultam a identificação dos indivíduos. Características apontadas por uma série de autores, como Ana Silvia Volpi Scott e Dario Scott (2013). Os sobrenomes não possuíam uma regra definida para transmissão aos descendentes. Isso se fossem transmitidos, pois troca, inversão ou abandono dos sobrenomes eram corriqueiros. Por sua vez, os prenomes eram escolhidos majoritariamente a partir de um conjunto reduzido em relação ao estoque total disponível, o que resultava em um alto índice de homônimos.

A constatação deste "problema" abriu novas possibilidades para o estudo das práticas de nominação. Rodrigo Weimer (2013, f. 323) as define como: 
As maneiras pelas quais os homens, em sociedade, atribuem, para si e para outrem, formas de denominação pessoal; as maneiras pelas quais manipulam, ocultam ou evidenciam em diversos contextos sociais tais denominações; as formas pelas quais, através de nomes, prenomes, e apelidos, os indivíduos relacionam-se com a história e com tradições herdadas; as formas pelas quais os nomes são operados no sentido de reiterar hierarquias sociais, afirmar estatutos, ou mesmo contestá-los.

Ou seja, muito além de uma simples listagem de nomes. Com efeito, Marc Bloch (1932, p. 67) já apontava a relação entre os nomes usados por uma sociedade com questões sociais, ao declarar que "a escolha dos nomes de batismo, sua natureza, sua frequência relativa [...] revelam correntes de pensamento ou de sentimento aos quais o historiador não pode permanecer indiferente" ${ }^{\text {"3 }}$.

\section{O nome e seus significados}

"Que há num simples nome?"4 Numa tentativa de responder a Julieta, pode-se apelar a Hamlet: num simples nome "há muita coisa

\footnotetext{
${ }^{3}$ Tradução nossa. Citação no idioma original: "Le choix même des noms de baptême, leur nature, leur fréquence relative [...] révèlent des courants de pensée ou de sentiment auxquels l'historien ne saurait rester indifférent".

${ }^{4}$ Frase retirada de Romeu e Julieta (Ato II, Cena II). Julieta, ao saber que Romeu é um Montecchio, disse a ele: "Meu inimigo é apenas o teu nome. Continuarias sendo o que és, se acaso Montecchio tu não fosses. Que é Montecchio? Não será mão, nem pé, nem braço ou rosto, nem parte alguma que pertença ao corpo. Sê outro nome. Que há num simples nome? O que chamamos rosa, sob uma outra designação teria igual perfume. Assim Romeu, se não tivesse o nome de Romeu, conservaria a tão preciosa perfeição que dele é sem esse título. Romeu, risca o teu nome, e, em troca dele, que
} 
mais [...] do que sonha nossa pobre filosofia" ${ }^{5}$. Atribuir um nome é um ato aparentemente corriqueiro, mas está longe de decorrer de uma escolha feita ao acaso. Envolve fatores complexos e nem sempre perceptíveis, como comportamentos, costumes, tradições, parentesco, moda, etc.

Para Claude Lévi-Strauss (2012), as funções principais do nome são as seguintes: identificar, significar e classificar. Identificação, segundo Martha Hameister (2006), é a função primária de um nome, presente em todas as culturas, ainda que com variações quanto à estrutura e às práticas de atribuição e transmissão.

Lévi-Strauss (2012) considera que o papel do nome não se restringe apenas à identificação. Para o antropólogo, “os nomes próprios fazem parte integrante de sistemas tratados por nós como códigos: modos de fixar significações, transpondo-as para os termos de outras significações” (LÉVI-STRAUSS, 2012, p. 201). Significar, afirma Robert Rowland (2008), faz com que o nome ganhe significados, que estabelecem a identidade pessoal e social da pessoa nominada.

não é parte alguma de ti mesmo, fica comigo inteira" (SHAKESPEARE, 2008, p. 39, grifo nosso).

${ }^{5}$ Frase retirada de Hamlet (Ato I, Cena V). Hamlet fala para Horácio: "Recebamo-lo, então, como estrangeiro. Há muita coisa mais no céu e na terra, Horácio, do que sonha a nossa pobre filosofia. Vide novamente. Jurai de novo, assim Deus vos ajude, por mais que eu me apresente sob aspecto extravagante, tal como em futuro é possível que eu venha a comportar-me, que jamais - se me virdes alguma hora cruzar assim os braços, ou a cabeça sacudir desse jeito, ou dizer frases sem nexo: 'Muito bem' ou 'Poderíamos se o quiséssemos', ou 'Vontade tenho de falar', ou discursos desse gênero - mostrareis saber algo. Que a divina Graça e a Misericórdia vos amparem" (SHAKESPEARE, 2008, p. 562, grifo nosso). 
A terceira função do nome, a classificação, inclui ou exclui indivíduos em um grupo devido ao seu nome. Pode-se classificar com o intuito de dominação, seja, citando João de Pina Cabral (2008), por atribuição discricionária de antropônimo a outra pessoa, por interdição de nomes que possuam algum tipo de rejeição ou proibição, ou por discriminação a formas alternativas de nominação que não o nome oficial. Ou com o fim de qualificação, pois, de acordo com Hameister (2006), atributos podem ser incorporados ao nome próprio de acordo com a história de vida do sujeito que o detém e com os feitos exercidos durante este período. A qualificação também pode ser considerada no sentido inverso, isto é, quando se recebe um nome que já tenha atributos incorporados.

Desse modo, chega-se à ideia trabalhada por Hameister (2006) do nome como um patrimônio imaterial familiar que incorporava várias "qualidades" e podia ser transmitido para seus sucessores. Nessa transmissão também entravam os atributos já vinculados ao nome, o que fazia com que a pessoa que recebesse um nome também pudesse herdar o prestígio do portador original. Ou seja, recebia uma herança imaterial, no sentido trabalhado por Giovanni Levi (2000).

Considerando esses fatores, a escolha de um nome, citando José Luiz da Veiga Mercer e Sérgio Nadalin (2008), está longe de ser um ato de liberdade absoluta, sendo regulada pelas normas do grupo social. Em outras palavras, o que Levi (2000, p. 46) chama de racionalidade limitada, ou seja, uma ação "fruto do compromisso entre 
um comportamento subjetivamente desejado e aquele socialmente exigido, entre liberdade e constrição". Assim, escolher um nome "do estoque usual exprime a adesão ao grupo; é um ato de pertencimento. Já a escolha que ignorar o acervo tradicional poderá significar afastamento em relação à comunidade de origem e busca de uma nova identidade social" (MERCER; NADALIN, 2008, p. 12).

Além das normas sociais, a escolha, administração e transmissão de um nome estavam ligadas a estratégias que os diversos grupos adotavam para tal. Por meio de uma estratégia, segundo Pierre Bourdieu (1990), os sujeitos atuam em um contexto de sociedade como jogadores, agindo e se adaptando conforme as demandas de um jogo social, mesmo sem obedecer estritamente às regras. Liberdade essa de improvisar, a qual permite a produção de inúmeras jogadas viáveis, possível só até os limites do jogo.

Logo, percebe-se que "há mais coisas num simples nome do que possa imaginar nossa vã filosofia”, o que reitera a busca por como esse elemento era tratado e utilizado pelas sociedades em diversas épocas. Como visto anteriormente, as práticas nominativas lusobrasileiras anteriores ao século XX tinham algumas peculiaridades em relação aos demais sistemas nominativos europeus. 


\section{Os nomes em Porto Alegre: dados quantitativos}

A produção historiográfica constatou que diversas paróquias de Portugal e Brasil possuíam diversos elementos comuns no tocante às práticas de nominação. Para Rowland (2008, p. 18), isso reforça a concepção de que os nomes possuem um significado para a sociedade, visto que:

Se os nomes próprios fossem, de facto, marcas sem significado, seria de esperar que a sua distribuição no interior de uma determinada população fosse aleatória e que a sua variedade fosse suficiente para eliminar [...] os riscos de confusão entre pessoas. E, mesmo admitindo que houvesse subpopulações espacial ou temporalmente específicas, facto esse que se poderia traduzir na existência de conjuntos regional e / ou cronologicamente específicos de nomes, a distribuição desses nomes no interior de cada uma dessas subpopulações deveria mesmo assim ser aleatória. [...] a existência de uma distribuição regular dos nomes próprios em qualquer população, ou a persistência dessa distribuição ao longo do tempo, constitui um indício seguro do carácter socialmente significativo das práticas de nomeação.

O nome era atribuído de forma distinta da atual. No ato de batismo, o neófito recebia apenas o prenome. Algumas referências historiográficas e etnográficas, como Hameister (2006) e Rowland (2008), afirmam que o papel de escolha do prenome cabia aos padrinhos, o que não impedia possível influência dos pais no processo (HAMEISTER, 2006). De todos os modos, as Constituições Primeiras 
do Arcebispado da Bahia preceituavam que os párocos não deveriam consentir com a eleição de nomes que não pertencessem a algum indivíduo beatificado ou canonizado pela Igreja Católica (VIDE, 2007), ordem nem sempre respeitada.

Amorim (1983, p. 213, grifos nossos) destaca que:

O nome próprio recebido no baptismo podia ter relação com os nomes próprios dos pais, avós ou outros familiares, com os nomes dos padrinhos, com os oragos das paróquias, com pontos altos do culto de determinados santos, mas tinha muito a ver com modas que se localizam perfeitamente no tempo e que ultrapassam as fronteiras das paróquias, mesmo as mais isoladas.

O sobrenome só aparecia no casamento ou depois que o sujeito atingisse independência econômica (AMORIM, 1983). Enquanto a maioria dos países europeus consolidou o modelo de nominação baseado na transmissão de nomes de família pela linhagem paterna (ROWLAND, 2008), Portugal e suas colônias não possuíam regras específicas para transmissão do nome de família. Um indivíduo podia receber o(s) sobrenome(s) de seu pai e/ou de sua mãe, ou mesmo de avós ou parentes mais distantes. Era comum irmãos portarem nomes de família diferentes um do outro.

Outra prática comum era o uso de segundos nomes, que podiam ser uma invocação religiosa (por exemplo, Maria da Conceição ou Ana de Jesus) ou então um ou mais prenomes adicionais. Segundos nomes passíveis de transmissão aos descendentes e que, por vezes, 
convertiam-se em nome de família. Quanto aos escravos, estes em geral portavam apenas o prenome.

No período de 1772 a 1835 , têm-se, para a população livre e forra de Porto Alegre, 12.844 registros de batismo (6.508 meninos e 6.336 meninas) e 9.554 assentos de óbito (5.711 do sexo masculino e 3.843 do sexo feminino). Quanto aos casamentos, 2.899 noivos e 2.891 noivas não eram escravos/as.

Nos batismos, os prenomes foram eleitos dentro de um estoque de 378 opções masculinas e 382 femininas (17,2 meninos por nome e 16,6 meninas por nome). A despeito dessa relativa variedade, a tendência, a exemplo de outras freguesias luso-brasileiras já estudadas, era a de concentração das escolhas entre os cinco prenomes mais utilizados. 
Tabela 1 - Frequência dos cinco prenomes masculinos mais usados na Matriz de Porto Alegre por sexo (1772-1835)

\begin{tabular}{c|c|c|c|c|c|c}
\hline & \multicolumn{3}{|c|}{ Masculino } & \multicolumn{3}{c}{ Feminino } \\
\hline & Nome & NA & \% & Nome & NA & \% \\
\hline 1 & José & 890 & 13,7 & Maria & 1.252 & 19,8 \\
2 & João & 715 & 11,0 & Ana & 453 & 7,1 \\
3 & Manuel & 698 & 10,7 & Francisca & 263 & 4,2 \\
4 & Antônio & 694 & 10,7 & Joaquina & 254 & 4,0 \\
5 & Francisco & 431 & 6,6 & Rita & 214 & 3,4 \\
\hline & Subtotal & $\mathbf{3 . 4 2 8}$ & $\mathbf{5 2 , 7}$ & Subtotal & $\mathbf{2 . 4 3 6}$ & $\mathbf{3 8 , 4}$ \\
& Outros 373 & 3.080 & 47,3 & Outros 377 & 3.900 & 61,6 \\
\hline & Total & $\mathbf{6 . 5 0 8}$ & $\mathbf{1 0 0}$ & Total & $\mathbf{6 . 3 3 6}$ & $\mathbf{1 0 0}$ \\
\hline
\end{tabular}

Fonte: NACAOB. Madre de Deus de Porto Alegre. Extração 22 abr. 2015.

A tendência à escolha de um dos cinco prenomes mais populares foi mais recorrente para o sexo masculino, com pouca variação de percentuais entre os quatro primeiros colocados. No sexo feminino, Maria, o prenome mais popular, teve mais que o dobro de recorrência em relação a Ana, segundo colocado.

Em comparação de Porto Alegre com outras freguesias lusobrasileiras contemporâneas ao período analisado ${ }^{6}$, os cinco prenomes masculinos mais populares, afora a posição dentro de cada ranking, não mudam. Já a frequência de uso desses prenomes é semelhante apenas

6 As localidades referenciadas são: Nossa Senhora das Necessidades (Florianópolis/SC), analisada por Sérgio Luiz Ferreira (2006), São José (Tiradentes/MG), por Douglas C. Libby e Zephyr Frank (2015), e São João (Ilha do Pico/Açores), estudada por Norberta Amorim (2003). 
entre as freguesias da América portuguesa. Na localidade açoriana são apresentados percentuais muito superiores ${ }^{7}$.

Referente aos prenomes femininos, o percentual de uso das cinco opções mais escolhidas em Porto Alegre também é semelhante ao das localidades da América Portuguesa e muito inferior ao da freguesia açoriana $^{8}$. Os cinco prenomes mais populares também possuem variações um pouco maiores que as apresentadas dentro do sexo masculino, apesar de Maria ser o mais utilizado em todas as localidades ${ }^{9}$.

Com este panorama, é esperado encontrar um alto número de homônimos devido à grande possibilidade de um batizando receber o mesmo nome de um ascendente consanguíneo ou espiritual. Aqui consideraremos os casos de filhos que recebem o mesmo prenome de um dos pais e de afilhados aos quais é atribuído um prenome idêntico ao de um dos padrinhos. Incluem-se na contagem os casos de prenome com gênero flexionado (por exemplo, uma Josefa filha de um José ou um Antônio afilhado de uma Antônia). O quadro encontrado apresenta que mais de $43 \%$ dos neófitos de Porto Alegre recebiam o mesmo

\footnotetext{
${ }^{7}$ Nas paróquias da América portuguesa, para os batizandos do sexo masculino, os percentuais variaram de 51,3 a 53,8\%, enquanto na açoriana, o índice ultrapassa os $90 \%$.

${ }^{8}$ Entre as batizandas do sexo feminino, o percentual das demais paróquias brasileiras ficou em torno de $45 \%$, enquanto a localidade açoriana apresentou índices de aproximadamente $66 \%$.

${ }^{9}$ No ranking de Nossa Senhora das Necessidades, em vez de Francisca, consta Luísa. $\mathrm{Na}$ freguesia açoriana, afora Maria, Ana e Francisca (apenas século XIX), os demais prenomes do ranking não são os mesmos das paróquias da América portuguesa.
} 
prenome dos pais e/ou padrinhos, percentual semelhante ao encontrado por Hameister (2003) para Rio Grande (42,9\%).

Tabela 2 - Origem dos prenomes (\%) dos indivíduos batizados na Matriz de Porto Alegre por sexo (1772-1835)

\begin{tabular}{c|c|c|c|c}
\hline & \multicolumn{2}{|c|}{ Masculino } & \multicolumn{2}{c}{ Feminino } \\
\hline Origem do prenome & NA & $\mathbf{\%}$ & NA & \% \\
\hline Pai/mãe & $\mathbf{1 . 3 5 1}$ & $\mathbf{2 0 , 8}$ & $\mathbf{1 . 0 6 1}$ & $\mathbf{1 6 , 7}$ \\
Só pai/só mãe & 858 & 13,2 & 634 & 10,0 \\
Padrinho/madrinha & $\mathbf{2 . 5 5 6}$ & $\mathbf{3 9 , 3}$ & $\mathbf{2 . 0 2 3}$ & $\mathbf{3 1 , 9}$ \\
Só padrinho/Só madrinha & 2.063 & 31,7 & 1.596 & 25,2 \\
Pais+padrinhos & $\mathbf{4 9 3}$ & $\mathbf{7 , 6}$ & $\mathbf{4 2 7}$ & $\mathbf{6 , 7}$ \\
\hline Subtotal & $\mathbf{3 . 4 1 4}$ & $\mathbf{5 2 , 5}$ & $\mathbf{2 . 6 5 7}$ & $\mathbf{4 1 , 9}$ \\
Outras origens & 3.094 & 47,5 & 3.679 & 58,1 \\
\hline Total Geral & $\mathbf{6 . 5 0 8}$ & $\mathbf{1 0 0}$ & $\mathbf{6 . 3 3 6}$ & $\mathbf{1 0 0}$ \\
\hline
\end{tabular}

Fonte: NACAOB. Madre de Deus de Porto Alegre. Extração 22 abr. 2015.

Essa prática era mais comum de ser adotada para rebentos do sexo masculino. Também se percebe que havia maior chance de receber o prenome de um dos padrinhos do que de um dos pais.

A respeito das motivações e estratégias que levariam à escolha e transmissão de determinados prenomes em detrimento de outros, a historiografia referente às práticas de nominação luso-brasileiras apresentou algumas possibilidades. De início, a já citada escolha de opções já existentes no repertório social e familiar como afirmação de pertencimento (MERCER; NADALIN, 2008). Mas também podia ser uma homenagem ao portador original do nome, um desejo de transmitir atributos juntamente com o nome ou, no caso de transmissão de prenomes entre padrinhos e afilhados, a consolidação das relações estabelecidas no compadrio (HAMEISTER, 2003; 2006). Para os 
libertos, o uso recorrente de nomes seria uma maneira de recriar ancestralidades e a própria memória do cativeiro (WEIMER, 2013).

Referente aos segundos nomes e nomes de família, devido ao já mencionado fato de aqueles por vezes serem utilizados com a mesma função destes, um problema para análises quantitativas é a dificuldade para estabelecer um limite preciso entre um e outro. Por conseguinte, neste momento não distinguiremos, para efeitos de análise, segundo nome de nome de família.

Uma possibilidade de análise, a partir do exame dos óbitos, é buscar estabelecer a partir de que faixa etária os indivíduos passam a agregar nomes ao de batismo. A partir de uma primeira análise, constatou-se que os indivíduos com até sete anos ${ }^{10}$ de idade, afora raras exceções, só portavam o prenome de batismo. Dos sete até os dezenove, os sobrenomes ou segundos nomes foram adotados por aproximadamente metade dos que faleceram nessa faixa etária. Quanto aos que faleceram com vinte anos ou mais, a grande maioria (91,4\% dos homens e $88 \%$ das mulheres) já tinha acrescentado algum nome.

Tal resultado indicia uma corroboração ao afirmado por Amorim (1983), que defende que o sobrenome era adotado com o casamento ou a independência econômica. Para aclarar a situação, um caminho é confrontar as variáveis "nomes além do prenome" e "status matrimonial ao falecer", comparando com a quantidade de indivíduos

\footnotetext{
${ }^{10}$ Para a Igreja, os indivíduos com até sete anos eram considerados inocentes, não suscetíveis ao pecado.
} 
que, no ato do casamento, tiveram segundos prenomes e/ou nomes de família registrados.

Tabela 3 - Percentual de falecidos livres e forros em Porto Alegre com nome(s) além do prenome por sexo e status matrimonial em comparação com percentual de noivos livres e forros em Porto Alegre com nome(s) além do

\begin{tabular}{|c|c|c|c|}
\hline & & nome (1772-1835) & Feminino (\%) \\
\hline \multicolumn{2}{|r|}{ Casamento } & 96,2 & 96,9 \\
\hline \multirow{4}{*}{ Óbito } & Solteiros/as & 92,5 & 78,4 \\
\hline & Casados/as ou viúvos/as & 96,1 & 94,0 \\
\hline & $\mathrm{N} / \mathrm{C}$ & 67,5 & 40,1 \\
\hline & Total & 85,9 & 78,9 \\
\hline
\end{tabular}

Fonte: NACAOB. Madre de Deus de Porto Alegre. Extração 22 abr. 2015.

Tanto entre os noivos no ato do matrimônio quanto entre os casados ou viúvos no ato do falecimento, a maioria absoluta foi registrada com segundos nomes e/ou sobrenomes, havendo variação pouco expressiva quanto ao gênero. Quanto aos solteiros, o percentual de homens com segundos nomes e/ou nomes de família é pouco inferior aos casados ou viúvos, enquanto entre as mulheres a diferença de percentual foi maior. Chama a atenção o caso dos falecidos sem registro de status matrimonial no óbito. Entre esses, segundos nomes e/ou sobrenomes tiveram uso bem menor do que entre os que tiveram o status matrimonial registrado. No caso das mulheres, mais da metade das sem registro do estado conjugal tinham apenas o prenome.

A onomástica luso-brasileira tradicionalmente afirma que as mulheres faziam menor uso de nomes de família em prol de segundos nomes. Entretanto, se forem considerados os segundos nomes como 
passíveis de transmissão para os descendentes, não se nota grande variação entre os gêneros quanto à origem familiar dos segundos nomes e/ou sobrenomes. Esta análise, desenvolvida a partir dos assentos de casamento de Porto Alegre, usou como amostragem os noivos considerados à época socialmente "desqualificados" e os noivos considerados à época socialmente "qualificados".

Tabela 4 - Origem do(s) segundo(s) nome(s) e/ou sobrenome(s) (\%) dos noivos (livres e forros) "qualificados" ou "desqualificados" que se casaram na Matriz de Porto Alegre (1772-1835)

\begin{tabular}{c|c|c|c|c|c|c|c|c}
\hline & \multicolumn{3}{|c|}{ "Qualificados” } & \multicolumn{3}{c}{ "Desqualificados” } \\
\hline & \multicolumn{2}{|c|}{ Feminino } & \multicolumn{2}{c}{ Masculino } & \multicolumn{2}{c}{ Feminino } & \multicolumn{2}{c}{ Masculino } \\
\hline Origem do(s) nome(s) & NA & $\mathbf{\%}$ & NA & $\mathbf{\%}$ & NA & $\mathbf{\%}$ & NA & $\mathbf{\%}$ \\
\hline Um nome & $\mathbf{1 8}$ & $\mathbf{6 , 5}$ & $\mathbf{1 2}$ & $\mathbf{8 , 3}$ & $\mathbf{1 6 3}$ & $\mathbf{3 1 , 2}$ & $\mathbf{1 3 0}$ & $\mathbf{3 4 , 1}$ \\
Pai & 8 & 2,9 & 7 & 4,9 & 5 & 1,0 & 8 & 2,1 \\
Mãe & 2 & 0,7 & 0 & 0,0 & 23 & 4,4 & 4 & 1,0 \\
Outra & 8 & 2,9 & 5 & 3,5 & 135 & 25,9 & 118 & 31,0 \\
\hline Dois ou mais nomes & $\mathbf{2 5 9}$ & $\mathbf{9 2 , 8}$ & $\mathbf{1 2 9}$ & $\mathbf{8 9 , 6}$ & $\mathbf{2 9 0}$ & $\mathbf{5 5 , 6}$ & $\mathbf{1 8 8}$ & $\mathbf{4 9 , 3}$ \\
Só pai & 22 & 7,9 & 33 & 22,9 & 4 & 0,8 & 8 & 2,1 \\
Só mãe & 11 & 3,9 & 0 & 0,0 & 29 & 5,6 & 0 & 0,0 \\
Pai e mãe & 38 & 13,6 & 7 & 4,9 & 1 & 0,2 & 0 & 0,0 \\
Pai e outra & 99 & 35,5 & 47 & 32,6 & 10 & 1,9 & 13 & 3,4 \\
Mãe e outra & 24 & 8,6 & 8 & 5,6 & 52 & 10,0 & 12 & 3,1 \\
Pai, mãe e outra & 12 & 4,3 & 7 & 4,9 & 1 & 0,2 & 0 & 0,0 \\
Só outra & 53 & 19,0 & 27 & 18,8 & 193 & 37,0 & 155 & 40,7 \\
\hline Subtotal & $\mathbf{2 7 7}$ & $\mathbf{9 9 , 3}$ & $\mathbf{1 4 1}$ & $\mathbf{9 7 , 9}$ & $\mathbf{4 5 3}$ & $\mathbf{8 6 , 8}$ & $\mathbf{3 1 8}$ & $\mathbf{8 3 , 5}$ \\
Só prenome & 2 & 0,7 & 3 & 2,1 & 69 & 13,2 & 63 & 16,5 \\
\hline TOTAL & $\mathbf{2 7 9}$ & $\mathbf{1 0 0}$ & $\mathbf{1 4 4}$ & $\mathbf{1 0 0}$ & $\mathbf{5 2 2}$ & $\mathbf{1 0 0}$ & $\mathbf{3 8 1}$ & $\mathbf{1 0 0}$ \\
\hline
\end{tabular}

Fonte: NACAOB. Madre de Deus de Porto Alegre. Extração 22 abr. 2015.

Se não são constatadas grandes diferenças entre homens e mulheres de condição social equivalente, o mesmo não se aplica entre 
estratos sociais diferentes. Os "desqualificados" em geral utilizavam menos nomes, sendo mais recorrentes nomes que não eram originários de nenhum dos pais. Contudo, é necessário relativizar os dados, pois muitos registros de casamento de noivos socialmente menos privilegiados não tinham registrados os pais dos nubentes. De todos os modos, o panorama apresentado corrobora a tese de Sérgio Luiz Ferreira (2006), que considera que a transmissão de nomes de família era uma questão de estrato social, e não de gênero.

Este cenário reitera a ideia do nome como um patrimônio imaterial com acesso desigual entre os diversos setores da sociedade. Cenário que reforça tanto a posição predominante dos setores localizados no topo da hierarquia quanto o papel subalterno dos membros da base da sociedade. Não obstante, retomando a noção de estratégia de Bourdieu (1990), pode-se dizer que, dentro dos limites impostos pela estratificação social, membros de setores sociais não pertencentes à elite poderiam "jogar" e utilizar seus nomes também como uma herança imaterial. Para deslindar e compreender melhor esses processos é necessário reduzir a escala de observação.

\section{Redução da escala: algumas considerações}

A despeito de suas inegáveis contribuições para o estudo das práticas de nominação, uma abordagem puramente quantitativa possui seus limites analíticos, o que já fora apontado por uma série de autores. 
Justo Serna e Anaclet Pons (2012) afirmam que a Itália da década de 1970 foi um dos primeiros locais onde surgiu uma proposta de estudos históricos que saísse do padrão macroanalítico vigente à época, caracterizado por grandes escalas, longa duração e métodos seriais. Em contraponto, surgiu a defesa de um modelo microanalítico, mais modesto e que permite a redução do objeto de investigação.

Ao contrário do que alguns podem imaginar, essa proposta pioneira não partiu de Ginzburg, mas de Edoardo Grendi. A partir da influência da antropologia e da economia, este autor destacava da primeira uma "vocação microanalítica" e da segunda "o estudo das relações sociais através de suas distintas manifestações econômicas ou extraeconômicas" (SERNA; PONS, 2012, p. 31). Isso gerou a defesa da redução da escala de observação, que, ao contrário da macroanálise de espaços nacionais, possibilitava a análise das relações sociais captando toda a densidade e complexidade das mesmas, utilizando-se como espaço a "comunidade".

Mediante uma renúncia ao teleologismo e ao referente normativo de medida nas análises, Grendi desenvolveu sua proposta que transita do micro doméstico ao macro mais amplo, com a "comunidade" como espaço intermediário. Sem embargo, sua contribuição mais lembrada é a do excepcional-normal, aqui entendida como, na falta de informações de primeira mão, o uso de documentos indiretos lidos nas entrelinhas (SERNA; PONS, 2012). 
Algum tempo depois, Ginzburg (1989a) apontou que a investigação quantitativa de longa duração, não obstante suas contribuições, pode distorcer os fatos observados e gerar uma história social homogeneizada. Processo que levou a muitos investigadores a realizarem análises próximas de fenômenos circunscritos. Reflexo, supõe o autor, das incertezas referentes a processos macro-históricos. Com a circunscrição do âmbito investigativo, é possível a sobreposição de séries documentais, guiadas pelo nome do indivíduo. Em outras palavras, o já anteriormente mencionado método onomástico (GINZBURG, 1989a), que não abandona a investigação serial, mas não considera o anonimato como horizonte analítico (SERNA; PONS, 2012).

O problema é como fazer uma investigação nominativa de grupos subalternos. Ao destacar a necessidade de escolher casos relevantes e significativos, Ginzburg retoma o excepcional-normal de Grendi. O sentido do termo foi ampliado para além do documento excepcional, chegando a objetos de investigação também extraordinários. Estes "funcionam como espias ou indícios de uma realidade oculta que a documentação, de um modo geral, não deixa transparecer" (GINZBURG, 1989a, p. 177).

O indício é retomado em outro ensaio do autor (GINZBURG, 1989b), onde são estabelecidas as diretrizes do paradigma indiciário. Com diversas influências, como a medicina, a psicanálise, o romance policial, o método de Giovanni Morelli para análise de obras de arte e a 
semiótica, o ensaio defende que, a exemplo da medicina, a história baseia-se em indícios, conjecturas e testemunhos indiretos. Não sendo possível acessar o passado diretamente, especialmente quando os vestígios são "excepcionais", "existem zonas privilegiadas - sinais, indícios - que permitem decifrá-la [a realidade opaca]" (GINZBURG, 1989b, p. 177). Ao se deparar com a questão do rigor em um campo onde predomina a dúvida, Ginzburg (1989b) defende abertamente um "rigor flexível" baseado na intuição - isto é, na conjectura e na chamada "imaginação controlada".

Levi (1992) traçou, a partir da experiência do que passou a se chamar micro-história, as principais concepções desta prática. Sua base é a redução da escala de observação, ao considerar que "fatos insignificantes e casos individuais podem servir para revelar um fenômeno mais geral" (LEVI, 1992, p. 158). O autor (1992, p. 159) ainda destaca "o debate sobre a racionalidade, a pequena indicação como paradigma científico, o papel do particular (não, entretanto, em oposição ao social), a atenção à capacidade receptiva e à narrativa, uma definição específica de contexto e a rejeição do relativismo".

De acordo com Serna e Pons (2012), a perspectiva microanalítica, até por ter sido desenvolvida anteriormente em outras disciplinas, ultrapassou as fronteiras da micro-história italiana e pode ser vista atualmente em diversas obras que não se intitulam com essa etiqueta. Um exemplo é o estudo de trajetórias individuais em estudos 
relativos à população e família (SCOTT; SCOTT, 2013), originalmente concebidos em bases quantitativas e seriais.

Nossa proposta é ir além do nome como mera ferramenta identificadora de indivíduos. Weimer (2013, f. 329-330) já alertara para o risco, cometido por muitos micro-historiadores, de se desprezar o papel simbólico dos nomes e as questões classificatórias e de significação envolvidas:

Os nomes não são apenas rastros a serem perseguidos. Eles não são neutros: traduzem relações de poder e hierarquias. Expressam formas de classificação social e disposições identitárias individuais, familiares ou grupais frente aos demais. Os nomes trazem impressos em si tradições, memórias e experiências vividas. Evidenciam formas de relacionar-se com o passado. A ele rendem homenagem e também projetam o que se espera do devir.

Há também a dinâmica dos nomes. Conforme alertou Weimer (2013), os nomes não são estanques, pois há a possibilidade de invenção, recriação ou modificação, sendo maleáveis de acordo com a interação entre os membros de uma comunidade.

\section{Nome e trajetórias: um exercício de possibilidades}

Seguindo essa linha de raciocínio é que se apresenta a proposta de trabalhar com a dinâmica dos nomes, visível apenas com a redução de escala e abordagem qualitativa de trajetórias individuais. Análise 
possibilitada, conforme anteriormente dito, mediante o cruzamento entre as atas paroquiais diversas. Neste momento, serão considerados nas trajetórias reconstituídas apenas os eventos registrados em Nossa Senhora Madre de Deus de Porto Alegre entre 1772 e 1835.

Como por enquanto, com exceção de uma escritura de alforria, não serão utilizadas outras fontes, é fundamental frisar que, pelas características e limitações das fontes paroquiais, serão analisados apenas os nomes oficiais, o que de forma alguma impede de se levar em conta que tal forma de nominação não era a única a ser usada por aquela sociedade. Novamente Weimer (2013) lembra que os nomes são plurais, visto que nem sempre o nome oficial era utilizado em todos os contextos. Havia a possibilidade de se utilizar, em âmbitos familiares, íntimos e comunitários, formas de nominação alternativas que continham uma série de implicações simbólicas. Para isso, seria necessário o cruzamento com processos judiciais ou com fontes que são inexistentes para o recorte temporal deste estudo, como as orais. Logo, as formas alternativas de nominação não serão abordadas aqui.

Reconstituição de trajetórias é uma prática relativamente difundida em investigações centradas em famílias de elite. Para estas, normalmente a documentação existente é mais abundante e possibilita maior acesso a dados. Famílias de setores subalternos, excetuando-se o caso de famílias de escravos, ainda são pouco pesquisadas pelos historiadores. Documentação mais reduzida, dificuldade maior de identificação devido a dados menos completos em registros, maior 
variação de nomes entre um ato e outro ou mesmo nomes de família mais irregulares ou inexistentes podem ser alguns dos fatores que dissuadem os pesquisadores da "empreitada".

Retomemos o princípio do excepcional-normal de Grendi (apud SERNA; PONS, 2012) e Ginzburg (1989a). Embora registros paroquiais possam, à primeira vista, parecer documentos "normais", lembremos que Levi afirma que, a rigor, todo documento pode ser excepcional. $\mathrm{O}$ que torna uma fonte normal ou excepcional é a forma como a mesma é lida - o excepcional está nas entrelinhas (informação verbal) ${ }^{11}$. Como a fonte paroquial via de regra registra todos os estratos sociais, podem ser encontrados, mediante cruzamento dos registros, casos excepcionais cujos dados permitam razoável identificação dos indivíduos ou cujos indícios possibilitem conjecturas com certo nível de segurança. Assim, excluem-se pessoas com nomes muito comuns, reduzindo-se a possibilidade de confusão com possíveis homônimos.

Optamos por tecer algumas considerações preliminares a respeito de uma análise da trajetória de uma família pertencente a setores sociais "não-qualificados" de Porto Alegre. Constituiu-se originalmente de uma parda forra, mãe solteira de cinco filhos naturais (ambos indicativos de "desqualificação" para a sociedade da época), chamada Ângela Francisca Coelho. Não se sabe sobre seu nascimento, mas sabe-se que faleceu aos sessenta anos e que deixou testamento.

11 Informação coletada em minicurso realizado por Giovanni Levi no seminário "Micro-História, Trajetórias e Imigração", realizado na Universidade Federal de Santa Maria, no dia 31 de outubro de 2014. 
Sabe-se também que foi alforriada ainda criança. De seu exproprietário, Francisco Coelho Osório, Ângela adotou o prenome como segundo nome e um sobrenome.

Ângela nunca se casou, mas, como já dito, teve registrados em Porto Alegre cinco filhos: José, Emerenciana, Timóteo, Angélica e Ana. Um de seus filhos, Timóteo José Rodrigues, se casou com Claudina Maria Assunção. Por sua vez, Ana Francisca do Vale teve um filho natural, apadrinhado por Angélica Francisca do Vale, que provavelmente era sua irmã.

Uma das filhas, Emerenciana Francisca do Vale, teve três filhos naturais: Luísa, Deolinda (falecida aos dois anos) e Bernardo, vindo a falecer em consequência do parto deste último (o filho faleceu um mês depois). No batismo de Luísa, Emerenciana foi registrada como "parda forra", nos demais não constava condição social. Já no de Bernardo consta o nome do pai, Joaquim Balbino Cordeiro. Curiosamente, o mesmo Joaquim casou-se com Luísa Francisca do Vale, filha de Emerenciana, meses após o falecimento da mãe da noiva.

De pronto, uma característica a ser apontada nessa família é a repetição de determinados nomes. As filhas mulheres acrescentaram os nomes "Francisca do Vale", o que foi seguido também por Luísa ao casar. Não se sabe de onde veio o sobrenome "do Vale". Por sua vez, Francisca, como anteriormente referido, era o segundo nome de Ângela.

Sobre a alteração de nomes entre registros, Ângela aparece apenas com o prenome no registro de batismo de Emerenciana; nos 
demais filhos, o nome está completo. Já nos assentos de batismo dos netos de Ângela, o sobrenome Coelho aparece quase todas as vezes, exceto no batismo de Luísa e dos filhos de Timóteo. A condição jurídica de Ângela aparece em todos os eventos ocorridos enquanto ela estava viva, exceto no batismo dos filhos José e Angélica.

Importante frisar duas informações cruciais no óbito de Ângela: ela deixa de ter o atributo de "forra" que tinha no nascimento de suas filhas e consta a existência de testamento, o que indicia um processo de ascensão social dessa família dentro das possibilidades da época. Seguramente nesse processo o nome familiar "Francisca do Vale" também passaria a ter um relativo prestígio.

Ferreira (2006), ao defender que a transmissão de nomes familiares à época era uma questão de classe, afirma que os integrantes de grupos subalternos costumavam abandonar seus sobrenomes devido a certo desprezo pelo nome de família ocasionado por não ter nada a herdar e/ou legar.

De fato, como visto em abordagem quantitativa acima apresentada, pessoas socialmente "desqualificadas" tendiam a utilizar menos os nomes de família. No entanto, o caso estudado permite considerar que tal "desprezo" não seja levado como regra absoluta. Ou seja, mesmo famílias que não pertenciam às elites podiam imprimir significado a seus nomes e manejá-los, evidentemente dentro de uma perspectiva de racionalidade limitada. Com efeito, Hameister (2006, f. 100) considera que "mesmo o mais pobre dos homens, o forro e o 
escravo, poderiam ter um bem a legar à sua descendência", que era o nome.

Para obter-se uma visão mais abrangente se este caso era isolado ou se acontecia com mais frequência, é necessário que sejam estudadas mais trajetórias de indivíduos e famílias de posição semelhante. Para que a investigação seja viável, devem ser buscados outros casos também relevantes e significativos, na acepção de Ginzburg (1989a). De qualquer forma, as considerações aqui apontadas lançam novas possibilidades para análises futuras.

\section{Considerações finais}

À guisa de conclusão, ficam claras as diversas potencialidades oferecidas pelos registros paroquiais de batismo, casamento e óbito, tanto para análises de caráter quantitativo quanto para estudos de trajetórias individuais e para investigações que utilizem-se das duas abordagens de forma combinada.

No caso apresentado, a combinação de métodos quantitativos e qualitativos possibilitou que o nome seja visto além de uma ferramenta metodológica e passe a ser também objeto de estudo, a partir dos problemas que as práticas nominativas luso-brasileiras impuseram ao uso do método onomástico. Além de dados como frequência dos prenomes em batismos, transmissão do nome a descendentes e uso de segundos nomes e/ou sobrenomes, também é possível vislumbrar como 
os indivíduos e famílias faziam uso de seus nomes (ao menos em contextos oficiais) ao longo de seus eventos vitais e também os possíveis significados que teriam dado a tais práticas.

Sobre as práticas de nominação em Porto Alegre, os dados e considerações aqui apresentados apontam para a importância que a sociedade da época depositava no nome. Isso implicava em estratégias para sua administração, como a tendência de serem atribuídos e transmitidos nomes já presentes na família e comunidade. Estratégias cujo acesso era possível dentro dos limites de uma sociedade estratificada e hierarquizada, configurando-se o nome como um patrimônio imaterial que confere prestígio ao seu portador de acordo com a sua posição em uma sociedade de desiguais. Com isso, o próprio acesso ao nome e a transmissão eram também desiguais.

\section{Referências}

AMORIM, Maria Norberta. Falando de demografia histórica... NEPS: boletim informativo, Guimarães, v. 33-34, p. 4-8, set./nov. 2003.

- Identificação de pessoas em duas paróquias do Norte de Portugal (1580-1820). Boletim de Trabalhos Históricos, Guimarães, v. XXXIV, p. 213-279, 1983.

BASSANEZI, Maria Silvia C. B. Registros paroquiais e civis: os eventos vitais na reconstituição da história. In: PINSKY, Carla Bassanezi; LUCA, Tânia Regina de (orgs.). O Historiador e suas fontes. São Paulo: Contexto, 2009. p. 141-172. 
BLOCH, Marc. Noms de personne et histoire sociale. Annales d'histoire économique et sociale, [s.1.], v. 4, n. 13, p. 67-69, 1932.

BOURDIEU, Pierre. Da regra às estratégias. In: Coisas ditas. São Paulo: Brasiliense, 1990. p. 77-95.

FERREIRA, Sérgio Luiz. "Nós não somos de origem": populares de ascendência açoriana e africana numa freguesia do sul do Brasil (17801960). Tese (Doutorado em História) - Programa de Pós-Graduação em História, Universidade Federal de Santa Catarina, Florianópolis, 2006.

GINZBURG, Carlo. O nome e o como: troca desigual e mercado historiográfico. In: GINZBURG, Carlo; CASTELNUOVO, Enrico; PONI, Carlo. A micro-história e outros ensaios. Lisboa: Difel, 1989. p. 169-178.

Sinais: raízes de um paradigma indiciário. In: GINZBURG, Carlo. Mitos, emblemas, sinais: morfologia e história. São Paulo: Companhia das Letras, 1989. p. 143-179.

HAMEISTER, Martha Daisson. Na pia batismal: estratégias de interação, inserção e exclusão social entre os migrantes açorianos e a população estabelecida na vila de Rio Grande, através do estudo das relações de compadrio e parentescos fictícios (1738-1763). In: CONGRESSO BRASILEIRO DE HISTÓRIA ECONÔMICA, 5, 2003, Caxambu. Anais eletrônicos... Campinas, ABPHE, 2003. Disponível em:

http://www.abphe.org.br/congresso2003/Textos/Abphe_2003_91.pdf. Acesso em: 15 maio 2010.

Para dar calor à nova povoação: estudo sobre estratégias sociais e familiares a partir dos registros batismais da vila do Rio Grande (1738-1763). Tese (Doutorado em História) - Programa de PósGraduação em História Social, Universidade Federal do Rio de Janeiro, Rio de Janeiro, 2006.

LEVI, Giovanni. A herança imaterial: trajetória de um exorcista no Piemonte do século XVII. Rio de Janeiro: Civilização Brasileira, 2000. 
Sobre a micro-história. In: BURKE, Peter (org.). A escrita da história: novas perspectivas. São Paulo: UNESP, 1992. p. 133-161.

LÉVI-STRAUSS, Claude. O pensamento selvagem. 12. ed. Campinas: Papirus, 2012.

LIBBY, Douglas C.; FRANK, Zephyr. Naming practices in Eighteenand Nineteen-Century Brazil: names, namesakes, and families in the parish of São José, Minas Gerais. Journal of Family History, Ottawa, v. 40, n. 1, p. 64-91, 2015.

MARCÍLIO, Maria Luiza. Os registros paroquiais e a História do Brasil. Varia Historia, Belo Horizonte, n. 31, p. 13-20, jan. 2004.

MERCER, José Luiz da Veiga; NADALIN, Sérgio Odilon. Um patrimônio étnico: os prenomes de batismo. Topoi, Rio de Janeiro, v. 9, n. 17, p. 12-21, jul./dez. 2008.

PINA CABRAL, João de. Recorrências antroponímicas lusófonas. Etnográfica, Lisboa, v. 12, n. 1, p. 237-262, maio 2008.

SCOTT, Ana Silvia Volpi; SCOTT, Dario. Análise quantitativa de fontes paroquiais e indicadores sociais através de dados coletados para sociedades do Antigo Regime. Mediações, Londrina, v. 18, n. 1, p. 106-124, jan./jul. 2013.

SERNA, Justo; PONS, Anaclet. O Buraco da Agulha. Do que falamos quando falamos da micro-história? In: MARTINS, Maria Cristina Bohn; MOREIRA, Paulo Roberto Staudt (orgs.). Uma história em escalas: a microanálise e a historiografia latino-americana. São Leopoldo: Oikos; Unisinos, 2012. p. 15-72.

SHAKESPEARE, William. Tragédias: teatro completo. Rio de Janeiro: Agir, 2008. 
WEIMER, Rodrigo de Azevedo. A gente da Felisberta: consciência histórica, história e memória de uma família negra no litoral riograndense no pós-emancipação (c. 1847 - tempo presente). Tese (Doutorado em História) - Programa de Pós-Graduação em História. Universidade Federal Fluminense, Niterói, 2013.

Artigo recebido em 02/07/2015, aceito em 14/02/2016 